\title{
A combination of viewing reaction time and incidental learning task in child molesters, rapists, and control males and females Orestis Giotakos*
}

\author{
Address: Hellenic Society for Research and Prevention of Sexual Abuse, Greece
}

* Corresponding author

from International Society on Brain and Behaviour: 2nd International Congress on Brain and Behaviour Thessaloniki, Greece. 17-20 November 2005

Published: 28 February 2006

Annals of General Psychiatry 2006, 5(SuppI I):SI I4 doi:I0.II86/I744-859X-5-SI-SII4

\section{Background \\ The present study was designed to explore the interference effects of sexual interest on viewing reaction time and cog- nitive functioning, in a group of sexual offenders.}

\section{Materials and methods}

In order to test this hypothesis, 31 rapists, 27 child molesters, 53 control males and 24 control females, were given in a PC a viewing reaction time task while being distracted with photographs of semi-nude males and females of various ages and other stimuli. In the second part of the experiment, the subjects were instructed to attempt to recall whether or not the photograph had been presented during the first part or whether it was novel.

\section{Results}

The results showed that extra familial child molesters had their longest viewing times with the photographs of girls, intra-familial child molesters and control women with the pictures of adolescent females, and rapists and control males with the photographs of women. The pattern of errors during the incidental learning task yielded several interesting findings. Intra- and extra-familial child molesters showed the best recognition with the photographs of boys and adolescents males. Especially, extra-familial child molesters showed the best recognition with photographs of boys, despite having looked at them for the shortest period of time, probably because of suppression. In general, the profile of child molesters seems to be between that of the control males' and the control females' profile, while the rapists' profile seems to have many common features with the control males' profile.

\section{Discussion}

In summary, viewing reaction time, in combination with incidental learning tasks, can serve as an unobtrusive measure of males' sexual interests. The results of this study encourage the development and use of such techniques in epidemiological studies, as well as on professionals working with children.

\section{References}

I. Quinsey VL, Ketsetzis M, Earls C, Karamanoukian A: Viewing time as a measure of sexual interest. Ethology and Sociobiology 1996, 17:34I-354.

2. Wright LW, Adams HE: Assessment of sexual preference using a choice reaction time task. Journal of Psychopathology and Behavioral Assessment 1994, 16:221-231.

3. Singer B: Conceptualizing sexual arousal and attraction. The Journal of Sex Research 1984, 20:230-240. 